\title{
Observation of the exhaust plume from the space shuttle main engines using the microwave limb sounder
}

\author{
H. C. Pumphrey ${ }^{1}$, A. Lambert ${ }^{2}$, and N. J. Livesey ${ }^{2}$ \\ ${ }^{1}$ School of GeoSciences, The University of Edinburgh, UK \\ ${ }^{2}$ NASA Jet Propulsion Laboratory, Pasadena, CA, USA
}

Received: 21 June 2010 - Published in Atmos. Meas. Tech. Discuss.: 30 August 2010

Revised: 23 December 2010 - Accepted: 19 January 2011 - Published: 24 January 2011

\begin{abstract}
A space shuttle launch deposits 700 tonnes of water in the atmosphere. Some of this water is released into the upper mesosphere and lower thermosphere where it may be directly detected by a limb sounding satellite instrument. We report measurements of water vapour plumes from shuttle launches made by the Microwave Limb Sounder (MLS) on the Aura satellite. Approximately $50 \%-65 \%$ of shuttle launches are detected by MLS. The signal appears at a similar level across the upper $10 \mathrm{~km}$ of the MLS limb scan, suggesting that the bulk of the observed water is above the top of the scan. Only a small fraction at best of smaller launches (Ariane 5, Proton) are detected. We conclude that the sensitivity of MLS is only just great enough to detect a shuttle sized launch, but that a suitably designed instrument of the same general type could detect the exhausts from a large proportion of heavy-lift launches.
\end{abstract}

\section{Introduction}

Water vapour is a significant trace constituent of the upper mesosphere and lower thermosphere regions of the Earth's atmosphere. It is found in mixing ratios of up to $7 \mathrm{ppmv}$ in the $70-80 \mathrm{~km}$ altitude range. Just below the cold summer mesopause the mixing ratio may be sufficient for condensation to occur, forming polar mesospheric clouds (PMC). Its mixing ratio decreases rapidly with altitude due to photolysis, providing the source of the hydroxyl radical $(\mathrm{OH})$ which in turn plays an important role in mesospheric chemistry. The seasonal cycle of water vapour in the upper mesosphere was first clearly observed by instruments on the UARS mission. It shows a strong annual cycle in the polar regions as ascent over the summer pole brings wetter air up from below, while

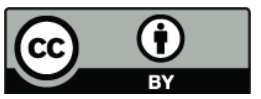

Correspondence to: H. C. Pumphrey (h.c.pumphrey@ed.ac.uk) descent over the winter pole brings dry air down from the vicinity of the mesopause into the polar vortex (Pumphrey and Harwood, 1997; Chandra et al., 1997). The moistening effect of the ascending air may be detected at altitudes as high as $85 \mathrm{~km}$; the detailed structure of the profile may be influenced by PMC formation and evaporation (Hervig et al., 2003; Summers et al., 2001). In addition to its seasonal behaviour, water vapour near the mesopause responds strongly to the 11-year solar cycle (Remsberg, 2010; Hartogh et al., 2010; Lübken et al., 2009).

It is only in the wet, dynamically-cooled air over the summer pole that polar mesospheric clouds can form. There have been many studies that have used ground-based observation to suggest that the incidence of these clouds is increasing over time (see e.g. Gadsden, 1997). Whether this increase can really be detected in ground-based observations has been disputed by Kirkwood et al. (2008) but a similar increase in frequency has recently been observed in a long-term satellite dataset (Shettle et al., 2009). It has been suggested that the increase is a direct result of the increase in $\mathrm{CO}_{2}$ and/or $\mathrm{CH}_{4}$ mixing ratios that has occurred over the same period (Thomas et al., 1989; Thomas and Olivero, 2001). The reasoning behind this suggestion is that $\mathrm{CO}_{2}$ is the main agent of radiative cooling in the upper mesosphere and oxidation of $\mathrm{CH}_{4}$ is the main source of water in the middle atmosphere. The suggestion is not universally accepted; other work (Lübken et al., 2009) suggests that multi-decadal changes in PMC may have other causes. Some mesospheric clouds appear to be man-made in a much more direct sense in that they form as the result of a rocket launch. These clouds are usually observed close to the launch site, but in the case of the shuttle they may also be observed in the region of the summer pole over the days following a launch (Kelley et al., 2010). This implies that in order to fully understand the connection between PMC and climate change, we need to account for the effects of rocket launches on the mesosphere. 
A rocket launch may deposit a considerable amount of water vapour in the Earth's atmosphere. The space shuttle is the largest launch vehicle currently operating: its main engines produce about 700 tonnes of $\mathrm{H}_{2} \mathrm{O}$ (Norquist, 1977) during the course of a launch, of which up to 300 tonnes (Stevens et al., 2003) is deposited between 100 and $115 \mathrm{~km}$ altitude. Other large launch vehicles in current use are considerably smaller. Ariane 5 produces about 170 tonnes of $\mathrm{H}_{2} \mathrm{O}$ (Arianespace, 2008) per launch. The Russian Proton launcher (ILS, 2009) burns 586 tonnes of hypergolic fuel per launch; this produces water at a rate of $350 \mathrm{~g} / \mathrm{kg}$ (Ross et al., 2004), giving about 200 tonnes of water per launch.

There have been a number of reports over recent years of the effects of rocket launches on the mesosphere. Perhaps the most striking images are those taken by GUVI (the Global UltraViolet Imager: Stevens et al., 2005; Meier et al., 2010). These observations are nadir-viewing images at an ultraviolet wavelength emitted by atomic $\mathrm{H}$, which results from photolysis of water vapour. It is also possible to observe the water vapour from a launch directly. The first report of this type of observation (Siskind et al., 2003) used data from the SABER (Sounding of the Atmosphere using Broadband Emission Radiometry) instrument: an infra-red limb sounder. In this paper we report the first observations using a millimetre-wave limb sounder of water vapour plumes deposited in the mesosphere by rocket launches.

\section{The MLS instrument}

The Microwave Limb Sounder (Waters et al., 2006) is a limb sounding instrument flown on NASA's Aura satellite (Schoeberl et al., 2006), which was launched in July 2004. Aura flies in a $705 \mathrm{~km}, 98^{\circ}$ inclination, sun-synchronous orbit. The MLS instrument consists of several heterodyne radiometers fed by a parabolic dish antenna whose field of view is scanned repeatedly across the Earth's limb. Each limb scan, known as a Major Frame or MAF, covers an altitude range from the ground to approximately $92 \mathrm{~km}$. Each limb scan contains 148 individual measurements known as Minor Frames (MIFs). The $121 \mathrm{MIFs}$ numbered from 3 to 123 are limb observations, with the remainder being used for purposes such as calibration. The MIFs for which the tangent point is in the upper mesosphere are spaced at intervals of approximately $2.4 \mathrm{~km}$. The field of view of the MLS antenna has a half-power beamwidth at the tangent point of $8 \mathrm{~km}$ in the horizontal and $4 \mathrm{~km}$ in the vertical. It lies in the orbit plane of Aura which means that all of the radiation received by the antenna is emitted by a narrow curtain of air, approximately $8 \mathrm{~km}$ wide, lying above the orbit track.

The output of the MLS radiometers is analysed by a number of spectrometers. Most of these are banks of 11 or 25 traditional electronic filters with individual filter widths varying from $6 \mathrm{MHz}$ to $100 \mathrm{MHz}$. In addition there are four digital autocorrelator spectrometers (DACS): these have 129 channels each of width $97.6 \mathrm{kHz}$ giving a total bandwidth of $12.5 \mathrm{MHz}$. (Approximately last 20 channels are not usable, so the useful bandwidth is $10.7 \mathrm{MHz}$.) In this paper we are concerned with only one DACS: the one designated Band 23 and covering the frequency range occupied by the 183.31 GHz spectral line of $\mathrm{H}_{2} \mathrm{O}$.

The calibrated spectral radiances from the MLS spectrometers are available to the scientific community and are known as the level $1 \mathrm{~B}$ data. For most scientific purposes a more useful set of data consists of vertical profiles of geophysical quantities including temperature, geopotential height and the mixing ratios of various atmospheric constituents. Such data are referred to as level 2 data; they are generated from the level 1B data using a procedure described by Livesey et al. (2006). Currently, the most recent version of the MLS data is version 2.2 .

\section{An observation of a shuttle plume}

We began a search for occurrences of unusually high water vapour mixing ratio by using the version 2.2 MLS water vapour product (Lambert et al., 2007). This dataset has the advantage that it is easy to obtain and to work with but the trade-off made between noise and vertical resolution has resulted in very low vertical resolution in the upper mesosphere, making interpretation of the profiles less than straightforward. A search for data that are more than 4 standard deviations above the mean turned up a number of cases of which the upper half of Fig. 1 shows one of the most obvious examples

The statistically unusual points in the retrieved $\mathrm{H}_{2} \mathrm{O}$ profiles are in the highest retrieved level: $0.001 \mathrm{hPa}$. Data at this level are not recommended for general use, so it was not clear how the statistical anomaly should be interpreted. In an attempt to understand it more clearly, the original radiance spectra were inspected. We show in Fig. 2 the measured spectra from the 13 scans corresponding to the 13 profiles in the centre of Fig. 1. For comparison we also show spectra from 13 scans at the same latitudes on the subsequent orbit. The orbits are separated by $24^{\circ}$ of longitude; it can be seen in Fig. 1 that the water vapour and radiance on this subsequent orbit shows no enhancement. It is clear that the enhancement in retrieved water vapour is indeed coincident with an enhancement of the $183 \mathrm{GHz}$ spectral line. That enhancement extends to the top of the limb scan and is of a similar magnitude between $85 \mathrm{~km}$ and $92 \mathrm{~km}$, implying that much of the unusually wet airmass lies above the upper limit of the limb scan.

The event shown in Figs. 1 and 2 occurs about $8 \mathrm{~h}$ after the launch of space shuttle mission STS-116. Our hypothesis is that the unusual MLS observations are caused by the water vapour emitted by the main engines of the shuttle. In order to examine the validity of this hypothesis, we performed a search for any similar events in the MLS record. 


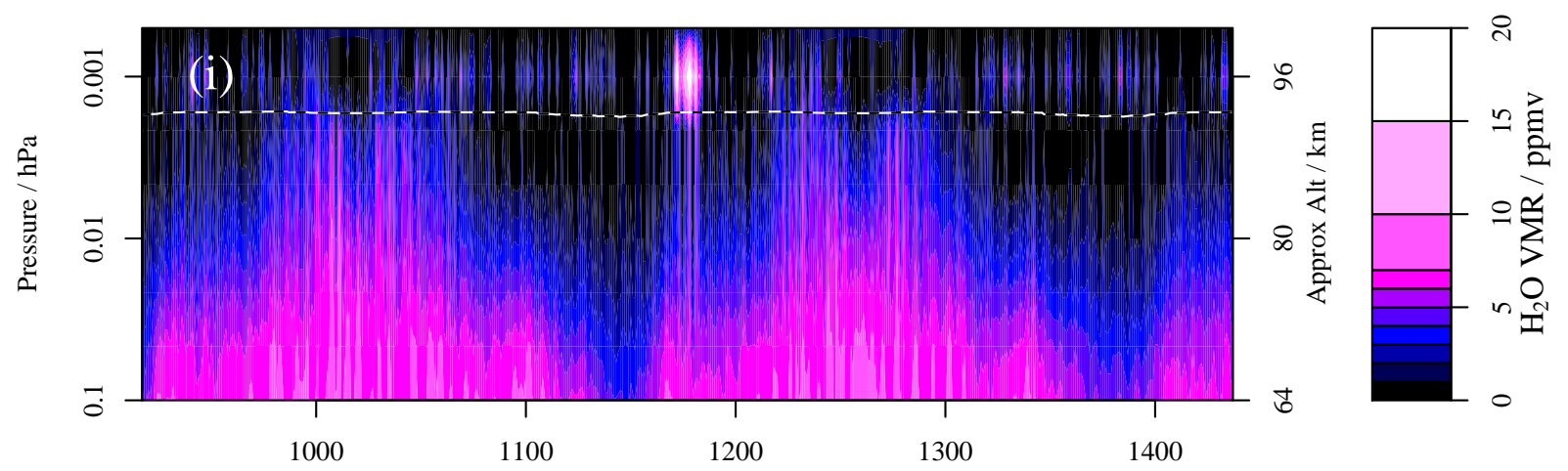

Profile Number

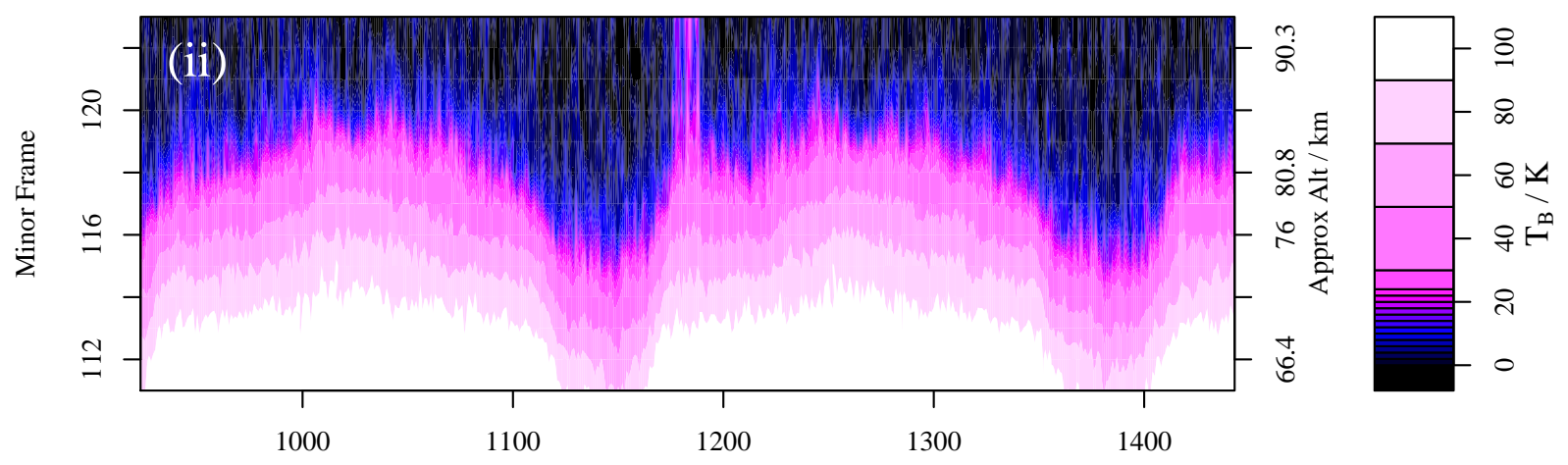

MAF Number

Fig. 1. Two orbits of MLS data in the mesosphere on 10 December 2006. The measurement location passes through $27^{\circ} \mathrm{N}$ heading southwards near the left-hand side, at the centre and near the right-hand side, that is, near profiles 936, 1176 and 1416. Panel (i) shows retrieved $\mathrm{H}_{2} \mathrm{O}$ mixing ratio in parts per million by volume (ppmv). Panel (ii) shows radiance (as Rayleigh-Jeans brightness temperature $T_{B}$ in K) averaged over the line centre region of the DACS. Retrieved profiles do not coincide exactly with limb scans (major frames or MAFs) for reasons described by Livesey et al. (2006), the profiles in (i) are aligned with the closest limb scan in (ii). The dashed line in (i) marks the upper boundary of the region in which the level $2 \mathrm{H}_{2} \mathrm{O}$ data are regarded as suitable for general use. The region of enhanced $\mathrm{H}_{2} \mathrm{O}$ and radiance in the centre of the plot lies between $18^{\circ} \mathrm{N}$ and $36^{\circ} \mathrm{N}$.

\section{Global search for similar events}

As the unusual observations only affect the version 2.2 retrieved water vapour product at an altitude that is not recommended for general use, we performed a search on the radiances. To reduce the dataset to a manageable size, we first averaged over the spectral channels which contain the $183 \mathrm{GHz}$ spectral line. At the altitudes that concern us here, the line lies within channels 48-56 of Band 23. Secondly, we subtracted a zonal mean value of the radiances to reduce the effect of the natural seasonal cycle in water vapour. Thirdly, we note that the event shown in Figs. 1 and 2 affects the top four minor frames in a limb scan; these lie at altitudes between 85 and $94 \mathrm{~km}$. We therefore took the mean of these to give a single number for each limb scan. Fourthly, we note that the event shown in Figs. 1 and 2 affects several consecutive limb scans. We therefore ran a low-pass filter over the time series generated by the previous step. Finally, we consid- ered an event to be detected if the result of the previous steps is more than 4 standard deviations away from the mean of the un-detected points. The choice of 4 standard deviations is somewhat arbitrary, but is a reasonable compromise between missing interesting events and making large numbers of false detections. The sequence of steps is shown in Fig. 3. We show the locations of all points detected by this procedure over the MLS mission to date in Fig. 4. It is notable that while there are many detections in the polar regions, there are few elsewhere except for a large cluster centred on Florida, from where space shuttle missions are launched. This suggests that the space shuttle might be responsible. To investigate this further, we plot in Fig. 5 the detections as a function of time and latitude. It is clear that all of the large detections in northern mid-latitudes coincide with shuttle launches, but that there are also shuttle launches that are not detected. The detections in the polar regions are clustered in the polar summers; as we note in the introduction it is at this time of year 

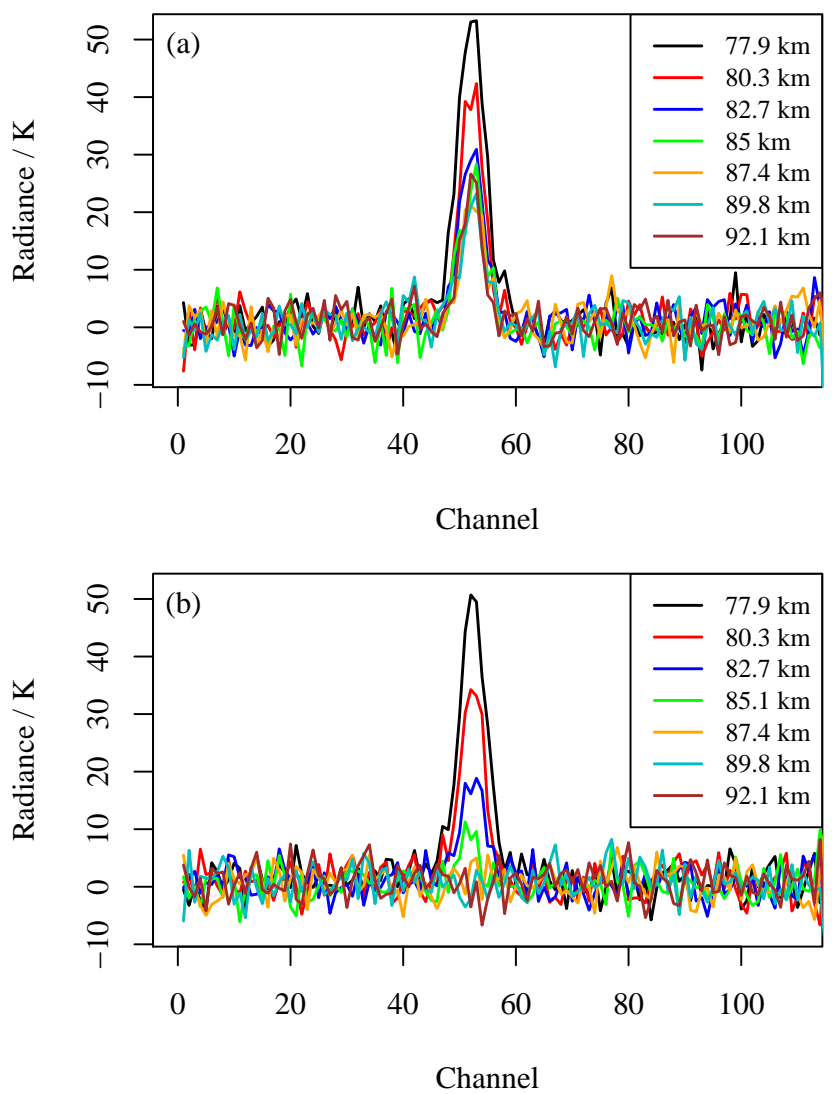

Fig. 2. (a) Mean spectra for 13 limb scans between $18^{\circ} \mathrm{N}$ and $36^{\circ} \mathrm{N}$ and at longitudes around $90^{\circ} \mathrm{W}$ on 10 December 2006: a region where the radiances are enhanced following a shuttle launch. (b) As (a), but one orbit later, so the latitudes are the same, but the longitudes are $25^{\circ}$ further west. Radiances here are typical for this latitude and season. (Radiances are again presented as RayleighJeans brightness temperature $T_{B}$ in K.)

that the polar mesosphere receives a large natural influx of water vapour. It seems likely that these polar detections are merely the response of our detection procedure to the natural processes (upwelling water vapour, PMC formation) which occur at this location and season.

We show in Table 1 a list of all shuttle launches in the study period indicating whether or not they were detected by MLS. The mean position of the detected plume is shown, together with a crude figure-of-merit to indicate the signal strength. If a plume from a given mission was observed on more than one orbit, then we show data for each such orbit separately.

\section{Discussion}

The results shown in Figs. 4 and 5 make it clear that, away from the polar summer, space shuttle launches are the main cause of unusually high mesospheric values in the MLS $183.3 \mathrm{GHz}$ data. MLS detects up to $63 \%$ of shuttle launches
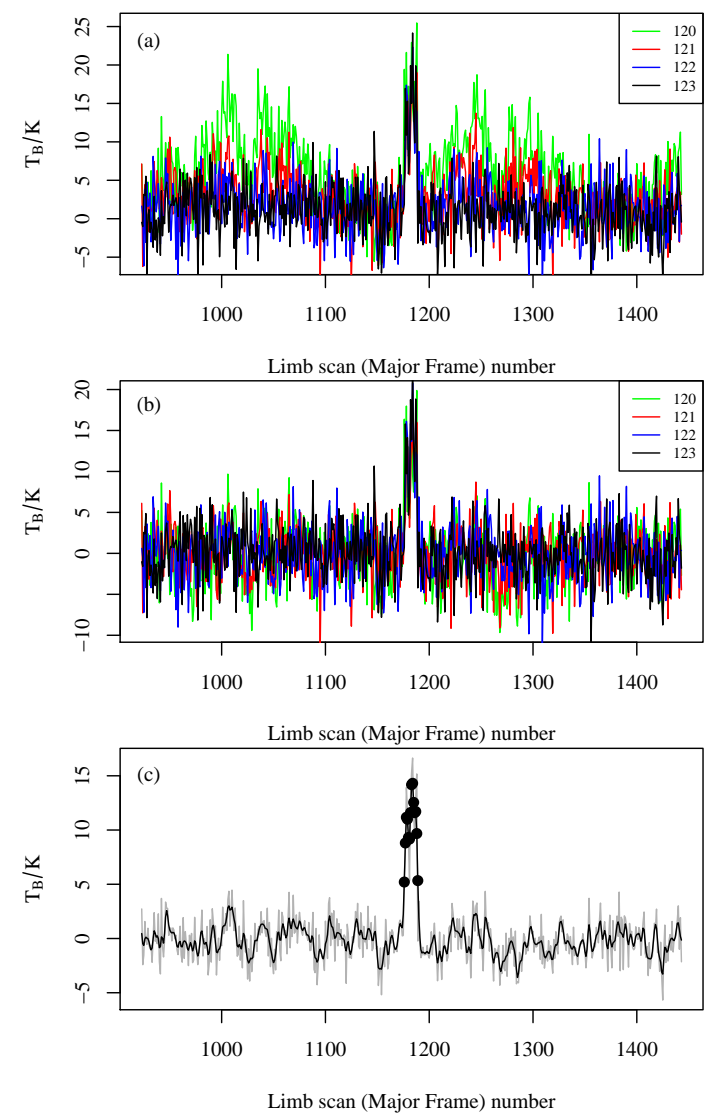

Fig. 3. The various stages used in the detection of unusual events in $\mathrm{MLS} \mathrm{H}_{2} \mathrm{O}$ in the upper mesosphere. Data are for the same two orbits as in Fig. 1. Panel (a) shows the radiance (as Rayleigh-Jeans brightness temperature $T_{B}$ in $\mathrm{K}$ ) averaged over the line centre channels, as in the panel (ii) of Fig. 1. Panel (b) shows the same data with a daily zonal mean subtracted. Panel (c) shows the data from (b) averaged over the four minor frames (grey) and then smoothed (black line). Black dots show the points which were finally detected as statistically unusual.

(12 launches out of 19) but the detection is marginal for two or three of these. The probability of detecting a smaller launch appears to be rather low. It is possible that the slight clustering of points near French Guiana are caused by launches of Ariane 5. The timing of these detections makes this seem likely: the four clearest detections in this region occur within $24 \mathrm{~h}$ of a launch. We show the timings in Table 2, noting that the three missions in that table make up less than $10 \%$ of the 31 Ariane 5 launches that occurred during the study period. It is also possible that the point near the Caspian sea is a launch from the Baikonur Cosmodrome. This detection occurred on 25 December 2006 at 22:10 UTC. This coincides with a Proton launch at 20:18 UTC on the same day. There were 44 Proton launches during the period studied here suggesting a detection probability on the order of $2 \%$. 


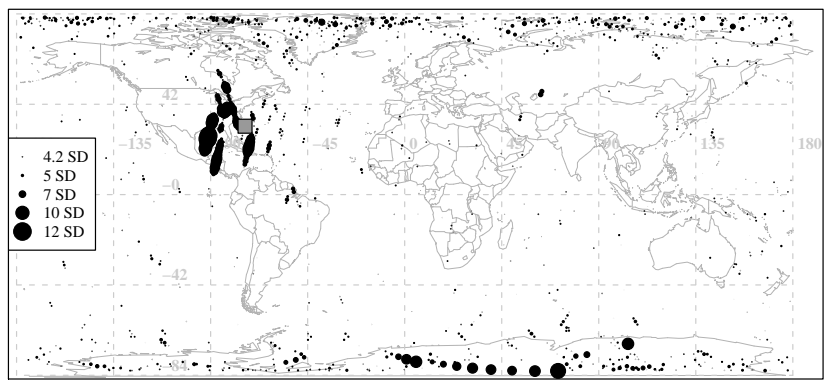

Fig. 4. Map of detected points. A point is shown if it is more than 4 standard deviations above the mean as described in the text and shown in Fig. 3. Dot size is proportional to the amount by which 4 standard deviations (SD) is exceeded. The grey square marks $31.5^{\circ} \mathrm{N}, 74^{\circ} \mathrm{E}$, which we assume to be the release point of the plume.

Siskind et al. (2003) report a much better success rate when detecting launches with the SABER instrument than we have achieved with MLS. We therefore conclude that SABER has a better sensitivity to water vapour plumes from rocket launches than does MLS. It seems likely that at least part of this greater sensitivity is due to the fact that the SABER limb scan reaches a higher tangent altitude than does that of MLS.

MLS observations are always made at the same two local times for a given latitude: early morning and early afternoon for tropics and mid-latitudes. Shuttle launches can and do take place at any time of day, so the delay between launch and plume observation is not fixed to any particular value. As table 1 shows, all but one of the detections occur within $\Delta t=26 \mathrm{~h}$ of the launch. The mean value of $\Delta t$ is $13.4 \mathrm{~h}$ with a standard deviation of $\pm 9 \mathrm{~h}$. This suggests that over the course of a day, the plume spreads out to an extent that its concentration becomes too small for MLS to detect, even though the increase in its horizontal extent must improve the chance that the MLS measurement track intersects the plume.

We may obtain a crude estimate of the rate at which the plume moves away from the launch path by finding the distance $\Delta r$ from the detection to the likely point of release and dividing this by $\Delta t$. The point of release we assume is not exactly at the launch site as the shuttle travels east as it rises: we assume a release point of $31.5^{\circ} \mathrm{N}, 74^{\circ} \mathrm{E}$ (Meier et al., 2010) as marked on Figs. 4 and 5. The resulting speeds have a mean of $44 \mathrm{~ms}^{-1}$ and a standard deviation of $29 \mathrm{~ms}^{-1}$. Calculating the meridional component alone gives a range of values between $-54 \mathrm{~ms}^{-1}$ and $+79 \mathrm{~ms}^{-1}$. We make no attempt to distinguish between advection and diffusion.

The speeds we obtain are of the same order of magnitude as the meridional velocities reported by Siskind et al. (2003), which vary from $6 \mathrm{~ms}^{-1}$ to $60 \mathrm{~ms}^{-1}$. They are also similar to the $44 \mathrm{~ms}^{-1}$ meridional speed of the plume observed by GUVI and reported by Stevens et al. (2005).

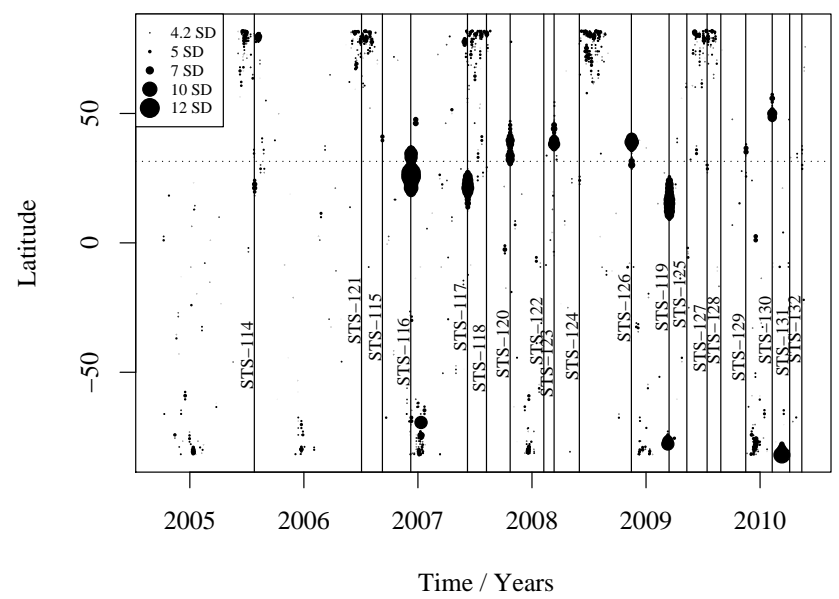

Fig. 5. Detected points as a function of time and latitude. The vertical lines mark the launch dates of space shuttle missions. Dot size is proportional to the amount by which 4 standard deviations (SD) is exceeded. The thin dotted line marks $31.5^{\circ} \mathrm{N}$ : approximately the latitude at which the plume is released.

The obvious plume detections shown in Fig. 4 are spread over 8-14 limb scans: about $1200-2200 \mathrm{~km}$ distance along the MLS measurement track. The plume itself may be considerably smaller than this, though. Approximately $400 \mathrm{~km}$ (2.3 limb scans) of the limb path are less than $3 \mathrm{~km}$ above the tangent height and $700 \mathrm{~km}$ (4 limb scans) are less than $10 \mathrm{~km}$ above the tangent height. MLS does not scan to a large enough tangent height to allow us to estimate the plume altitude, but SABER measurements (Siskind et al., 2003) suggest that it is at about $100 \mathrm{~km}$, at which altitude even a very compact plume could affect seven consecutive limb scans. This in turn suggests that the plumes detected by MLS have real horizontal extents ranging from rather small up to $1200 \mathrm{~km}\left(8 \mathrm{limb}\right.$ scans or $\left.10.5^{\circ}\right)$. Successive Aura orbits are separated by $25^{\circ}$ of longitude, which at the latitudes of interest is between $1800 \mathrm{~km}$ and $2400 \mathrm{~km}$. It is therefore statistically likely that a plume of this size could fall between two MLS orbits and not be observed, and could have become too tenuous for MLS to detect before the next MLS observation in the relevant location. This may explain why MLS does not detect all shuttle launches.

MLS was not designed to detect rocket launches and, although we have shown that it can do so, it clearly does not do so very well. The main reason for reporting the observations in the literature is to prevent any possibility that they might be misinterpreted as being caused by a natural phenomenon. If, however, it was desired to detect rocket launches from a satellite, a suitably designed microwave limb sounding instrument could prove very effective. Such an instrument would clearly need to scan across an altitude range between $80 \mathrm{~km}$ and $140 \mathrm{~km}$ to be sure of obtaining measurements with the plume at the tangent height. It would also need to have 
Table 1. Shuttle launches and MLS observations of them. A launch that was observed by MLS appears once for each MLS orbit on which it was observed. The "Obs delay" column is the number of hours between the launch time and the MLS observation. A launch that MLS failed to detect has NA in the last five columns. The latitude and longitude of the observation are mean values for all of the detected points on an orbit. The speed is the distance between this mean position and the assumed plume release location, divided by the observation delay. The strength is simply the sum of the amounts by which each of the individual detections on an orbit exceed 4 standard deviations.

\begin{tabular}{lccrrrrr}
\hline Mission & $\begin{array}{c}\text { Launch } \\
\text { date }\end{array}$ & $\begin{array}{c}\text { Launch } \\
\text { time }\end{array}$ & $\begin{array}{r}\text { Obs delay } \\
\text { /hours }\end{array}$ & Obs Lon & Obs Lat & $\begin{array}{r}\text { Speed } \\
\text { m/s }\end{array}$ & Strength \\
\hline STS-132 & $2010-05-14$ & $14: 20-E D T$ & NA & NA & NA & NA & NA \\
STS-131 & $2010-04-05$ & $06: 21-E D T$ & NA & NA & NA & NA & NA \\
STS-130 & $2010-02-08$ & $06: 21-E D T$ & 8.32 & -84.07 & 52.18 & 81.5 & 45.8 \\
STS-129 & $2009-11-16$ & $14: 28-E S T$ & 22.59 & -70.41 & 35.86 & 7.22 & 20 \\
STS-129 & $2009-11-16$ & $14: 28-E S T$ & 11.6 & -75.41 & 26.39 & 14 & 8.7 \\
STS-128 & $2009-08-28$ & $23: 59-E D T$ & NA & NA & NA & NA & NA \\
STS-127 & $2009-07-15$ & $06: 03-E D T$ & 20.62 & -68.7 & 28.59 & 8.14 & 13.7 \\
STS-125 & $2009-05-11$ & $14: 01-E D T$ & NA & NA & NA & NA & NA \\
STS-119 & $2009-03-15$ & $19: 43-E D T$ & 8.063 & -86.82 & 17.41 & 70 & 87.3 \\
STS-126 & $2008-11-14$ & $19: 55-E S T$ & 6.833 & -83.87 & 35.25 & 40.9 & 62.7 \\
STS-124 & $2008-05-31$ & $17: 02-E D T$ & 10.63 & -85.21 & 24.13 & 35.9 & 13.5 \\
STS-123 & $2008-03-11$ & $02: 28-E D T$ & 37.23 & -101 & 53.64 & 24.4 & 8.77 \\
STS-123 & $2008-03-11$ & $02: 28-E D T$ & 26.05 & -92.73 & 48.39 & 26.1 & 8.4 \\
STS-123 & $2008-03-11$ & $02: 28-E D T$ & 12.48 & -85.6 & 41.86 & 34.4 & 50.6 \\
STS-122 & $2008-02-07$ & $14: 45-E S T$ & NA & NA & NA & NA & NA \\
STS-120 & $2007-10-23$ & $11: 38-E D T$ & 14.93 & -65.32 & 41.83 & 25.7 & 14.2 \\
STS-120 & $2007-10-23$ & $11: 38-E D T$ & 2.937 & -79.58 & 38.85 & 90.9 & 74.5 \\
STS-118 & $2007-08-08$ & $18: 36-E D T$ & NA & NA & NA & NA & NA \\
STS-117 & $2007-06-08$ & $19: 38-E D T$ & 7.137 & -72.35 & 21.32 & 44.5 & 84.6 \\
STS-116 & $2006-12-09$ & $20: 47-E S T$ & 6.287 & -90.72 & 27.84 & 73.5 & 121 \\
STS-115 & $2006-09-09$ & $11: 15-E D T$ & 3.45 & -81.53 & 40.3 & 95.8 & 10.5 \\
STS-121 & $2006-07-04$ & $14: 38-E D T$ & NA & NA & NA & NA & NA \\
STS-114 & $2005-07-26$ & $10: 39-E D T$ & 15.43 & -63.08 & 21.18 & 28.4 & 25.7 \\
\hline
\end{tabular}

Table 2. Ariane 5 launches which appear to coincide with MLS observations of enhanced water vapour. A launch that was observed by MLS appears once for each MLS orbit on which it was observed. The "Obs delay" column is the number of hours between the launch time and the MLS observation.

\begin{tabular}{cccr}
\hline Mission & $\begin{array}{c}\text { Launch } \\
\text { date }\end{array}$ & $\begin{array}{c}\text { Launch } \\
\text { time }\end{array}$ & $\begin{array}{r}\text { Obs delay } \\
\text { /hours }\end{array}$ \\
\hline V-178 & $2007-10-05$ & $22: 02-U T C$ & 7.297 \\
V-188 & $2009-05-14$ & $13: 12-U T C$ & 3.38 \\
V-188 & $2009-05-14$ & $13: 12-U T C$ & 15.78 \\
V-193 & $2009-12-18$ & $16: 26-U T C$ & 0.7467 \\
\hline
\end{tabular}

several viewing directions in the horizontal, so that the longitudinal distance between observations was sufficiently small to capture most plumes. The instrument would also require either a receiver with lower noise and/or one operating at the frequency of a stronger water vapour line than the $183 \mathrm{GHz}$ line used by MLS.

\section{Conclusions}

We have demonstrated that the Microwave Limb Sounder (MLS) on Aura is capable of detecting the plume of water vapour deposited in the mesopause region and lower thermosphere by the main engines of the space shuttle. More than half of all shuttle launches are observed with the launches of smaller vehicles being in most cases difficult or impossible to detect against the background noise. The observed plume of water appears to disperse at a rate consistent with earlier observations.

Acknowledgements. Work at the Jet Propulsion Laboratory, California Institute of Technology, was carried out under a contract with the National Aeronautics and Space Administration. HCP thanks the University of Edinburgh for granting the sabbatical time during which this paper was written.

Edited by: G. Stiller 


\section{References}

Arianespace: Ariane 5 user's manual, Arianespace, Boulevard de l'Europe BP 17791006 Evry-Courcouronnes Cedex-France, 5 edn., 2008.

Chandra, S., Jackman, C. H., Fleming, E. L., and Russell III, J. M.: The seasonal and long term changes in mesospheric water vapor, Geophys. Res. Lett, 24, 639-642, 1997.

Gadsden, M.: The secular changes in noctilucent cloud occurrence: study of a 31-year sequence to clarify the causes, Adv. Space. Res., 20, 2097-2100, 1997.

Hartogh, P., Sonnemann, G. R., Grygalashvyly, M., Song, L., Berger, U., and Lübken, F.-J.: Water vapor measurements at ALOMAR over a solar cycle compared with model calculations by LIMA, J. Geophys. Res, 115, D00117, doi:10.1029/ 2009JD012364, 2010.

Hervig, M., McHugh, M., and Summers, M. E.: Water vapor enhancement in the polar summer mesosphere and its relationship to polar mesospheric clouds, Geophys. Res. Lett, 30, 2041, doi: 10.1029/2003GL018089, 2003.

ILS: Proton launch system mission planner's guide, International Launch Services, International Launch Services 1875 Explorer Street, Suite 700 Reston, Virginia 20190 USA, 7 edn., 2009.

Kelley, M. C., Nicolls, M. J., Varney, R. H., Collins, R. L., Doe, R., Plane, J. M. C., Thayer, J., Taylor, M., Thurairajah, B., and Mizutani, K.: Radar, lidar, and optical observations in the polar summer mesosphere shortly after a space shuttle launch, J. Gephys. Res., 115, A05304, doi:10.1029/2009JA014938, 2010.

Kirkwood, S., Dalin, P., and Réchou, A.: Noctilucent clouds observed from the UK and Denmark - trends and variations over 43 years, Ann. Geophys., 26, 1243-1254, 2008, http://www.ann-geophys.net/26/1243/2008/.

Lambert, A., Read, W., Livesey, N., Santee, M., Manney, G., Froidevaux, L., Wu, D., Schwartz, M., Pumphrey, H., Jimenez, C., Nedoluha, G., Cofield, R., Cuddy, D., Daffer, W., Drouin, B., Fuller, R., Jarnot, R., Knosp, B., Pickett, H., Perun, V., Snyder, W., Stek, P., Thurstans, R., Wagner, P., Waters, J., Jucks, K., Toon, G., Stachnik, R., Bernath, P., Boone, C., Walker, K., Urban, J., Murtagh, D., Elkins, J., and Atlas, E.: Validation of the Aura Microwave Limb Sounder middle atmosphere water vapor and nitrous oxide measurements, J. Geophys. Res, 112, D24S35, doi:10.1029/2007JD008752, 2007.

Livesey, N. J., Snyder, W. V., Read, W. G., and Wagner, P. A.: Retrieval algorithms for the EOS Microwave Limb Sounder (MLS) instrument, IEEE Trans. Geosciences and Remote Sensing, 44, 1144-1155, 2006.

Lübken, F.-J., Berger, U., and Baumgarten, G.: Stratospheric and solar cycle effects on long-term variability of mesospheric ice clouds, J. Geophys. Res, 114, D00I06, doi:10.1029/ 2009JD012377, 2009.

Meier, R. R., Plane, J. M. C., Stevens, M. H., Paxton, L. J., Christensen, A. B., and Crowley, G.: Can molecular diffusion explain Space Shuttle plume spreading?, Geophys. Res. Lett., 37, L08101, doi:10.1029/2010GL042868, 2010.

Norquist, L.: External tank for the space shutle main propulsion system, J. Spacecraft, 14, 358-364, 1977.
Pumphrey, H. C. and Harwood, R. S.: Water vapour and ozone in the mesosphere as measured by UARS MLS, Geophys. Res. Lett., 24, 1399-1402, 1997.

Remsberg, E.: Observed seasonal to decadal scale responses in mesospheric water vapor, J. Geophys. Res, 115, D06306, doi: 10.1029/2009JD012904, 2010.

Ross, M. N., Danilin, M. Y., Weisenstein, D. K., and Ko, M. K. W.: Ozone depletion caused by $\mathrm{NO}$ and $\mathrm{H} 2 \mathrm{O}$ emissions from hydrazine-fueled rockets, J. Geophys. Res, 109, D21305, doi: 10.1029/2003JD004370, 2004.

Schoeberl, M. R., Douglass, A. R., Hilsenrath, E., Bhartia, P. K., Barnett, J., Beer, R., Waters, J., Gunson, M., Froidevaux, L., Gille, J., Levelt, P. F., and DeCola, P.: Overview of the EOS Aura Mission, IEEE Trans. Geosci. Remote Sensing, 44, 1066-1074, 2006.

Shettle, E. P., DeLand, M. T., Thomas, G. E., and Olivero, J. J.: Long term variations in the frequency of polar mesospheric clouds in the Northern Hemisphere from SBUV, Geophys. Res. Lett, 36, L02803, doi:10.1029/2008GL036048, 2009.

Siskind, D. E., Stevens, M. H., Emmert, J. T., Drob, D. P., Kochenash, A. J., III, J. M. R., Gordley, L. L., and Mlynczak, M. G.: Signatures of shuttle and rocket exhaust plumes in TIMED/SABER radiance data, Geophys. Res. Lett, 30, 1819, doi:10.1029/2003GL017627, 2003.

Stevens, M. H., Gumbel, J., Englert, C. R., Grossmann, K. U., Rapp, M., and Hartogh, P.: Polar mesospheric clouds formed from space shuttle exhaust, Geophys. Res. Lett, 30, 1546, doi: 10.1029/2003GL017249, 2003.

Stevens, M. H., Meier, R. R., Chu, X., DeLand, M. T., and Plane, J. M. C.: Antarctic mesospheric clouds formed from space shuttle exhaust, Geophys. Res. Lett., 32, L13810, doi: 10.1029/2005GL023054, 2005.

Summers, M. E., Conway, R. R., Englert, C. R., Siskind, D. E., Stevens, M. H., Russell III, J. M., Gordley, L. L., and McHugh, M. J.: Discovery of a water vapour layer in the arctic summer mesosphere: Implications for polar mesospheric clouds., Geophys. Res. Lett, 28, 3601-3604, 2001.

Thomas, G. and Olivero, J.: Noctiluent clouds as possible indicators of global change in the mesosphere, Adv. Space. Res., 28, 937946, 2001.

Thomas, G. E., Olivero, J. J., Jensen, E. J., Schroeder, W., and Toon, O. B.: Relation between increasing methane and the presence of ice clouds at the mesopause, Nature, 338, 490-492, 1989.

Waters, J. W., Froidevaux, L., Harwood, R., Jarnot, R., Pickett, H., Read, W., Siegel, P., Cofield, R., Filipiak, M., Flower, D., Holden, J., Lau, G., Livesey, N., Manney, G., Pumphrey, H., Santee, M., Wu, D., Cuddy, D., Lay, R., Loo, M., Perun, V., Schwartz, M., Stek, P., Thurstans, R., Boyles, M., Chandra, S., Chavez, M., Chen, G.-S., Chudasama, B., Dodge, R., Fuller, R., Girard, M., Jiang, J., Jiang, Y., Knosp, B., LaBelle, R., Lam, J., Lee, K., Miller, D., Oswald, J., Patel, N., Pukala, D., Quintero, O., Scaff, D., Snyder, W., Tope, M., Wagner, P., and Walch, M.: The Earth Observing System Microwave Limb Sounder (EOS MLS) on the Aura satellite, IEEE Trans. Geoscience and Remote Sensing, 44, 1106-1121, 2006. 